\title{
BMJ Open 'Engage me in taking care of my heart': a grounded theory study on patient- cardiologist relationship in the hospital management of heart failure
}

\author{
Serena Barello, ${ }^{1}$ Guendalina Graffigna, ${ }^{1}$ Elena Vegni, ${ }^{2}$ Mariarosaria Savarese, ${ }^{1}$ \\ Federico Lombardi, ${ }^{3}$ A Claudio Bosio ${ }^{1}$
}

To cite: Barello S,

Graffigna G, Vegni E, et al. 'Engage me in taking care of my heart': a grounded theory study on patient-cardiologist relationship in the hospital management of heart failure. BMJ Open 2015;5:e005582. doi:10.1136/bmjopen-2014005582

- Prepublication history for this paper is available online. To view these files please visit the journal online (http://dx.doi.org/10.1136/ bmjopen-2014-005582).

Received 28 April 2014 Revised 29 August 2014 Accepted 9 September 2014

CrossMark

For numbered affiliations see end of article.

Correspondence to

Dr Serena Barello;

serena.barello@unicatt.it

\section{ABSTRACT}

Objective: In approaching the study and practice of heart failure (HF) management, authors recognise that the patient-doctor relationship has a central role in engaging patients in their care. This study aims at identifying the features and the levers of HF patient engagement and suggestions for orienting clinical encounters.

Design: Using a grounded theory approach, we conducted 22 in-depth interviews (13 patients with HF, 5 physicians and 4 caregivers). Data were collected and analysed using open, axial and selective coding procedures according to the grounded theory principles.

Settings: All interviews were conducted in an office in a university hospital located in a metropolitan area of Milan, Italy.

Participants: The data comprised a total of 22 patient, hospital cardiologist and caregiver interviews. Patients aged $\geq 18$ years with New York Heart Association (NYHA) Functional Class of II or III were eligible to take part. Patients were recruited primarily through their referral cardiologist.

Results: The HF patient engagement process develops in four main phases that are characterised by different patients' emotional, cognitive and behavioural dynamics that contribute to shape the process of a patient's meaning making towards health and illness regarding their care. The emerging model illustrates that HF patient engagement entails a meaning-making process enacted by the patient after the critical event. This implies patients' ability to give sense to their care experience and to their disease, symptomatology and treatments, and their changes along their illness course. Doctors are recognised as crucial in fostering patients' engagement along all the phases of the process as they contribute to providing patients with self-continuity and give new meaning to their illness experience.

Conclusions: This study identifies the core experiential domains and the main levers involved in driving patients with HF to effectively engage in their disease management. The model emerging from this study may help clinicians think in a fresh way about encounters with patients and their role in fostering their patients' health engagement.

\section{Strengths and limitations of this study}

- This study provides an evidence-based model of heart failure patients' engagement in their disease management and casts light on the individual and relational processes that occur when this process develops.

- This study strongly highlights the crucial role of physician in fostering the engagement process as their behaviours may reinforce or challenge the patient's ability to engage in the healing process. This model also underlines the importance of not merely fostering patients' health literacy but also providing behavioural education. Patients should be supported in the process of emotional elaboration of their illness experience and identity reconfiguration.

- The study adopted a qualitative research approach in order to deeply analyse the patients' lived experiences, by 'giving voice' to their experiences and unmet needs.

- In order to improve the study evidence, better articulated data collection and analysis according to patient's age and comorbidity-including patients affected by advanced heart failurewould be worthwhile.

- A better understanding of the possible role of the general practitioner in managing heart failure patients may be valuable for translating this study's implications from the hospital setting to ambulatory care.

\section{INTRODUCTION}

Heart failure (HF) affects about $2 \%$ of the Western population, with the prevalence increasing sharply from $1 \%$ in 40 -year-old individuals to $10 \%$ in those above the age of 75 years. ${ }^{1} \mathrm{HF}$ is a complex clinical syndrome of symptoms that suggests impairment of the heart as a pump supporting physiological circulation. Over recent decades, the capacity of health professionals to address the burden of $\mathrm{HF}$ has increased through the introduction of novel pharmacological agents, 
technological devices and non-pharmacological strategies. ${ }^{2}$ However, these treatments are often complex and require infrastructure and support to promote adherence and optimise patients' health outcomes. This fact makes the patients' capacity to effectively engage in their care a crucial factor for obtaining positive health outcomes and to reduce cost of care. Optimal outcomes and quality of life for patients with HF depend on engagement in effective self-care activities. ${ }^{3-5}$ The literature suggests that high-quality doctor-patient relations have been linked to higher levels of patient compliance with treatment plans, enhanced self-management of disease, greater recall of important treatment information, and improved general mental and physical health status. ${ }^{6}$ Studies ${ }^{7}$ have shown that the ability of doctors to engage patients in an effective care relationship is likely to make a difference in whether the consultation reinforces or discourages health actions that will maximise an HF patient's capacity to live positively with a chronic condition. Thus, the failure of health professionals to engage patients as effective and skilled selfmanagers of their health can lead to poor clinical outcomes. ${ }^{8}$ Self-care is comprised of a complex set of activities and unfortunately most clinicians are not adequately prepared to assist their patients to engage in effective self-care. ${ }^{9}$ Although pockets of excellence exist in $\mathrm{HF}$ management and there is a growing consensus that engaging patients is an essential component to the successful management of $\mathrm{HF}^{10-15}$ significant heterogeneity emerges in defining an HF patient's engagement goals and how to achieve them. In recent years, patients, physicians, ethicists, researchers and policymakers advocated for higher collaboration between doctors and patients ${ }^{16}$ in managing the disease. Patient engagement in the care process is described as the golden standard within a patient centred model of care, where clinicians engage patients as equal partners to make choices about healthcare, based on clinical evidence and patients' informed preferences and care expectations. ${ }^{17}{ }^{18}$ In order to optimally manage their condition, patients with HF need good knowledge of their condition, its typical symptoms and the significance of any changes in their symptoms. ${ }^{4}$ In addition, patients need to understand the purpose and likely side effects of their drug therapy. Furthermore, living with HF is recognised to have physical, emotional, cognitive, social and vocational consequences that affect the patient's adjustment to the illness. ${ }^{19}$ Adjusting to the illness involves changing one's lifestyle, being aware of one's physical ability and disability, developing coping strategies and adjusting to medication. ${ }^{20}$ Failure in patient-doctor relational quality might impair patients' self-management skills as well as their promptness in seeking medical treatment in the light of changing symptoms, and might be the cause of patients' lack of compliance to the healthy diet and drug therapies prescribed. $^{21} \mathrm{~A}$ recent review showed that when patients experienced poor quality of care they reported lack of confidence in care providers, confusion and delays in seeking care, and were deterred from maintaining positive self-care practices. $^{22}$ Furthermore, the crucial role of health providers in fostering patient engagement in healthcare needs to be acknowledged ${ }^{323}$; currently, no studies explore the perspective of the patients with $\mathrm{HF}$ when engaging in their health management or examine what the role of their doctors is in this process. Surprisingly, the extant scientific literature on this topic highlights an absence of the 'direct voice' of patients with HF about their health engagement experience. Moreover, studies aimed at discussing patient engagement mainly involve patients with chronic diseases (ie, diabetes, hypertension, asthma) that do not feature frequent episodes, such as HF does, of exacerbation and acute symptoms leading to recurrent hospitalisation. Those studies do not provide evidence of the levers that allow patients to effectively advance in the process of engagement with their disease management.

Previous research with patient affected by other chronic diseases provided cues about how to engage patients in healthcare. ${ }^{24-29}$ In particular, a recent study ${ }^{30}{ }^{31}$ highlighted that patient engagement is a multiphase process based on a conjoint cognitive, emotional and behavioural enactment of patients towards their health condition that develops in four main phases. In the present research we aimed at investigating if these features of the engagement process may be consistent with the case of patients with HF who constitute a very specific clinical population characterised by an unexpected acute event that has a deep impact on the patient's identity and emotional response. On the basis of these points, this study was aimed at investigating the levers of the HF patient engagement process and, in particular, which features of the patient-doctor relationship are needed to enhance it.

\section{METHODS}

The study was qualitative in its nature and designed according to the methodology of grounded theory (GT) ${ }^{32}$ GT is a qualitative research methodology aimed at developing theoretical explanations of emerging psychosocial phenomena grounded into data. ${ }^{33}$ In this study, it was essential to understand how the process of HF patient engagement evolves and which dynamics-specifically related to the patient-doctor relationship-may foster it. GT generates in-depth and context-based knowledge from the participants' unique perspective, informing the development of tailored and context-based interventions, which may, in turn, be more likely to lead to successful and sustainable programmes. Our study report conforms to COREQ criteria for reporting qualitative research. ${ }^{34}$

\section{Study setting and participants}

Theoretical sampling was used in the recruitment of participants and in data collection. ${ }^{35}$ Theoretical sampling allows the researcher to progressively recruit patients according to the emerging evidences in order to collect insights to corroborate those findings. According to this 
sample strategy, patients with differing experiences of HF (based on their functional class, risk factors and time from diagnosis) and with different attitudes to their health management (based on the level of patient activation according to the Patient Activation Measure score obtained in the screening phase) were involved. Theoretical sampling guided the selection of further participants and led to involve some hospital cardiologists and caregivers in order to collect further insights to corroborate the results emerging from the patient sample. Since HF is a complex problem with a high rate of treatment failures and re-hospitalisations, and is therefore more optimally managed with the guidance of specialists, we decided to interview hospital cardiologists. Moreover, data emerging from the patient's interviews showed the pivotal role of public hospital cardiologists for the patients involved in the study. General practitioners (GPs) are mainly consulted for general health advice and not for specialised consultations. We stopped sampling when we reached data saturation, that is, when no new emergent themes were generated from interview data. ${ }^{35} 36$ Patients were recruited from among hospital ambulatory out-patients in an Italian university hospital on the basis of the following inclusion criteria: (1) patients hospitalised with $\mathrm{HF}$ at the recruitment site; (2) New York Heart Association (NYHA) Functional Class of II or III $^{37} 38$ at least 6 months before the time of recruitment; and (3) could speak and understand Italian. Exclusion criteria were (1) patients aged below 18 years; (2) cognitive impairment based on a MMSE ${ }^{39}$ score of greater than 24; and (3) impaired vision or hearing, as documented in the medical record or by observation, such that neither an interview nor completing written forms was possible. The hospital cardiologists who agreed to collaborate in the study were specifically asked to identify patients more capable of self-management (NYHA functional class II or III), as we wanted to collect successful stories of patient engagement in order to better understand the factors that foster or hinder it, to effectively engage in their care. They were also requested to ask the patients whether they would participate in an interview. If the patient agreed, the researcher would then give the patient more information about the study, reassure the patient that all participation was voluntary, and ask for written informed consent. In order to avoid the potential stress of a hospital environment, the interviews took place in an office within the university hospital where the study was conducted. A Patient Activation Measure ${ }^{40}$ was administered to each patient who agreed to be involved in the study to assess their level of activation towards health and healthcare. The Patient Activation Measure is a 13-item measure that assesses patient knowledge, skill and confidence for selfmanagement. It is a valid and reliable instrument also tested in the cardiological field. ${ }^{41}$

This measure allows building of a sample based on different levels of patient activation to collect a wide range of patient engagement experiences. These differences were taken into account when building the conceptual model emerging from this study.

Physicians were recruited from the same hospital where the research took place. To be included they had to: (1) be experienced in caring for patients with cardiovascular diseases and (2) have at least 3 years of clinical experience in this clinical field. Caregivers were purposively selected based on clinicians' suggestions. To be included, caregivers had to be the primary caregiver of a HF patient for at least 2 years since diagnosis in order to be sure of having gathered enough informative experience of caregiving.

All participants provided informed consent after the purpose of the study was thoroughly explained to them.

\section{Data collection}

Interviews took place at the site of recruitment in a university office and were conducted from October 2013 to February 2014. The interviews, which were audiotaped with participants' permission, were semistructured and lasted on average for $45 \mathrm{~min}$. The researcher did not previously know the patients and doctors/caregivers participating in the study. Integrative diagrams and memos were also written throughout the process in order to better illuminate data analysis. Demographic (gender, age, marital status and socioeconomic data) and clinical information (NYHA functional status, time from diagnosis, risk factors for cardiovascular disease) were also collected. A psychologist, with expertise in qualitative methods (SB), conducted in-depth interviews to elicit patient's extended narratives about their illness journey, their ways of coping with HF, their health engagement experience and the role of professionals and informal caregivers in sustaining it (see table 1). According to the theoretical sampling strategy, the interviews from the patients lead to selection of other participants-such as cardiologists and caregivers-based on the problems that are unveiled through the progress of the research process. Cardiologists and caregivers were asked to discuss data emerging from the patients' interviews and to describe in their perspective what patient engagement means in healthcare and what factors may hinder or foster its realisation.

\section{Data analysis}

Data analysis was independently conducted by two researchers (SB, GG) and took place alongside data collection, to allow a progressive focusing of interviews and testing of tentative hypotheses. Integral transcripts were analysed according to the procedure of GT analysis. GT requires three sequential phases of coding: a first analysis step, named 'open coding', that implies a preliminary identification of concepts that fit the data; a second analysis step, 'axial coding', that consists of the progressive aggregation and condensation of codes into broader categories; and a final analysis step, 'selective coding', consisting of the abstraction from the data and the interpretive detection of connections among categories in 
Table 1 Interview guide for patients

Content areas
Living with heart failur
Coping with heart
failure

health engagement experience

\section{Questions} failure?
1. Please, can you describe your illness journey from diagnosis up to the present?

2. What are, if any, the main events that feature in your illness journey?

3. Overall, how well do you feel and do you think you are able to manage your heart

4. What are your difficulties in managing your disease and the medical prescriptions connected to it?

5. Please tell me, in your own words, what does it mean for you to be engaged in your own care?

6. What are the factors that, in your experience, may facilitate or hinder your involvement in medical decisions and disease management?

7. What are the features of the relation with your physician that facilitate your engagement?

8. What is the role of your family/informal network in supporting you in being more actively engaged in your own care?

9. What kinds of support and resources would be most helpful to support your engagement with your care?

order to find the 'core category' (ie, the pivotal concept that articulates the whole process under investigation)..$^{31}$ Diagrams and memos written along the data collection were also analysed according to the GT principles and contributed to build the emerging theory. The complex and systematic GT coding procedure was aimed at describing the elements implied in the development of the patient engagement experience. Data analysis was assisted by the computer package QSR NVivo $10,{ }^{40}$ which allowed the systematic treatment of data, keeping explicit track of all coding steps.

NVivo 10 allowed the researchers to build a theoretical model of HF patient engagement by exploring and statistically weighting associative connections among emergent categories. Integrative diagrams and memos collected throughout the process were used to guide thinking and three of the authors (SB, GG and EV) had several meetings to discuss their analytical insights and interpretations. After iterative discussion over many weeks between SB, GG and EV, a consensus on themes was finally reached. Two cardiologists not included in the interviews were finally asked to review the clinical coherence and relevance of emergent themes as key informants. $^{42}$

\section{RESULTS}

Twenty-two interviews were conducted, 13 patients were recruited. Their mean age was 68 years (range 54-85). Six lived alone and presented risk factors for developing cardiovascular diseases. Other interviews were addressed to five physicians experienced in managing cardiovascular diseases and four caregivers involved in supporting a cardiac patient in managing his/her own care (see table 2 for a detailed account of the final sample). None of the potential participants refused to be involved in the study.

\section{The patient engagement trajectories: a four-phase meaning-making process}

This study showed that the HF patient engagement process develops in four main phases, thus confirming previous evidences emerging from a previous study on patients with diabetes. These phases are characterised by different patients' emotional, cognitive and behavioural dynamics that contribute to shape the process of a patient's meaning making towards health and illness regarding their care. The passage from one phase to another is featured by patients' identity reconfiguration turning points that led individuals to progressively accept their new status (ie, as patients) and to interlace effective care relationships with their doctors. Our study particularly revealed the crucial role of cardiologists in helping patients to effectively engage in their self-care. This process also features the progressive reconnection with valued aspects of the self (featuring the patient's life before the disease onset), and the development of new and meaningful identities according to the new health condition. This allows patients to provide selfcontinuity and, at the same time, to give new meaning to their life experience (see figure 1). To illuminate the study findings presented below, we have selected representative participants' quotations that illustrate typical responses as well as the diversity of views expressed.

\section{Overcoming the blackout: giving sense to the critical incident}

In the 'blackout' phase, patients fall in an initial state of emotional, behavioural and cognitive blackout determined by the critical event (ie, the HF), which is described as unexpected and out of their control. They feel as if 'in suspension' as they are looking forward to a ruling from someone.

The critical event is depicted by patients as distressing and unacceptable because they have not yet acquired effective coping strategies to manage their new health condition, and they are not aware about what has 


\begin{tabular}{|c|c|c|}
\hline & Male & Female \\
\hline & $\mathrm{N}=9$ & $\mathrm{n}=4$ \\
\hline \multicolumn{3}{|l|}{ Patient $N=13$} \\
\hline \multicolumn{3}{|l|}{ Age (years) } \\
\hline Under 65 & 5 & 1 \\
\hline $65-74$ & 3 & 2 \\
\hline $75-84$ & 1 & 1 \\
\hline \multicolumn{3}{|l|}{ NYHA functional status } \\
\hline II & 6 & 4 \\
\hline III & 3 & 0 \\
\hline \multicolumn{3}{|l|}{ Time from diagnosis } \\
\hline $6-12$ months & 3 & 1 \\
\hline $1-4$ years & 3 & 1 \\
\hline $5-10$ years & 2 & 2 \\
\hline $11-20$ years & 1 & 0 \\
\hline \multicolumn{3}{|l|}{ Risk factors } \\
\hline Hypertension & 1 & 1 \\
\hline Heredity & 3 & 0 \\
\hline Hypercholesterolaemia & 0 & 1 \\
\hline Low physical activity & 1 & 1 \\
\hline Obesity & 1 & 0 \\
\hline Smoking & 1 & 0 \\
\hline Multiple risk factors & 2 & 0 \\
\hline \multicolumn{3}{|l|}{ Level of patient activation } \\
\hline 1 & 1 & 0 \\
\hline 2 & 3 & 1 \\
\hline 3 & 3 & 1 \\
\hline 4 & 2 & 2 \\
\hline \multicolumn{3}{|l|}{ Marital status } \\
\hline Married & 7 & 3 \\
\hline Living alone & 2 & 1 \\
\hline \multicolumn{3}{|l|}{ Annual family income } \\
\hline Up to $€ 20000$ & 3 & 1 \\
\hline$€ 20000-€ 50000$ & 5 & 2 \\
\hline \multirow[t]{2}{*}{ More than $€ 5000$} & 1 & 1 \\
\hline & $\mathrm{N}=3$ & $\mathrm{n}=2$ \\
\hline \multicolumn{3}{|l|}{ Physician $\mathrm{N}=5$} \\
\hline \multicolumn{3}{|l|}{ Age (years) } \\
\hline Under 40 & 1 & 1 \\
\hline $40-60$ & 2 & 1 \\
\hline \multicolumn{3}{|c|}{ Professional experience (years) } \\
\hline $6-10$ & 1 & 1 \\
\hline \multirow[t]{2}{*}{$>10$} & 2 & 1 \\
\hline & $\mathrm{N}=3$ & $n=1$ \\
\hline \multicolumn{3}{|l|}{ Caregivers $N=4$} \\
\hline \multicolumn{3}{|l|}{ Age (years) } \\
\hline Under 50 & 1 & 0 \\
\hline $50-80$ & 2 & 1 \\
\hline \multicolumn{3}{|l|}{ Status } \\
\hline Partner & 2 & 1 \\
\hline Son & 1 & 0 \\
\hline
\end{tabular}

happened to their body. This patient status contributes to patients often denying the diagnosis and not accepting the signs and symptoms. In this phase, patients also feel incapable of acting on and managing their diagnosis as they are generally uninformed about its nature and the exacerbating causes.
When it happened, I felt like in a black out...I felt as my head was a black box with troubles in focusing on everything. (55-year-old female patient with NYHA Class III HF)

You know, maybe it is taken for granted, but it is not that the heart failure, one day, calls you and tells you that it is coming! It is totally unpredictable! (54-year-old male patient with NYHA Class II HF)

To overcome the emotional confusion connected with the disrupting critical event, the patient declares a need clear information to realise what has happened. Moreover, when patients get the diagnosis, their emotional reaction is often an expression of shock, isolation and grief. In this situation, the physician is asked to support them by making an empathic response.

[...] at the beginning, after the diagnosis, patients seem to be frozen. Their horizon is totally absorbed by the thought of not being able to explain themselves what happened to them. Their horizon is totally dark. (Physician)

When I was diagnosed with heart failure, I feel totally paralyzed and the only think I wished in that moment was to understand and have an explanation about what happened to my body, to me, to my life. (54-year-old female patient with NYHA Class III HF)

I should have gone to hospital sooner with the shortness of breath and swollen ankles. But I didn't think it was anything serious. I just didn't know. I never heard of it...And what happened really at first, it comes on very gradual. (74-year-old female patient with NYHA Class III HF)

In that moment I can't understand what my doctor told me...the medical jargon is too difficult when you have no idea of what health failure is! (56-year-old male patient with NYHA Class II HF)

Patients expect informative action from their referential hospital cardiologist who becomes, since the moment of the diagnosis, the privileged interlocutor for the patient along the care process. The physician who carefully listens to the patient and provides the needed information allows the patient to enter the engagement process. In this phase, the physician is considered a 'gatekeeper'. The doctor is a catalyst for the patients' advancement in the engagement process by providing them with the key to read and to understand what happened to their body. If patients cannot legitimate the physician in this role they tend to have dysregulated emotional and behavioural responses often ending with the patient dropping out of care. In this phase, informal caregivers as well as their patients are mainly under shock and the caregivers cannot really act as supportive figures to help their loved one in effectively managing the disease.

At the beginning of the journey [with the disease] the doctor has to make you feel safe and should hang around with you and giving the key to understand what 


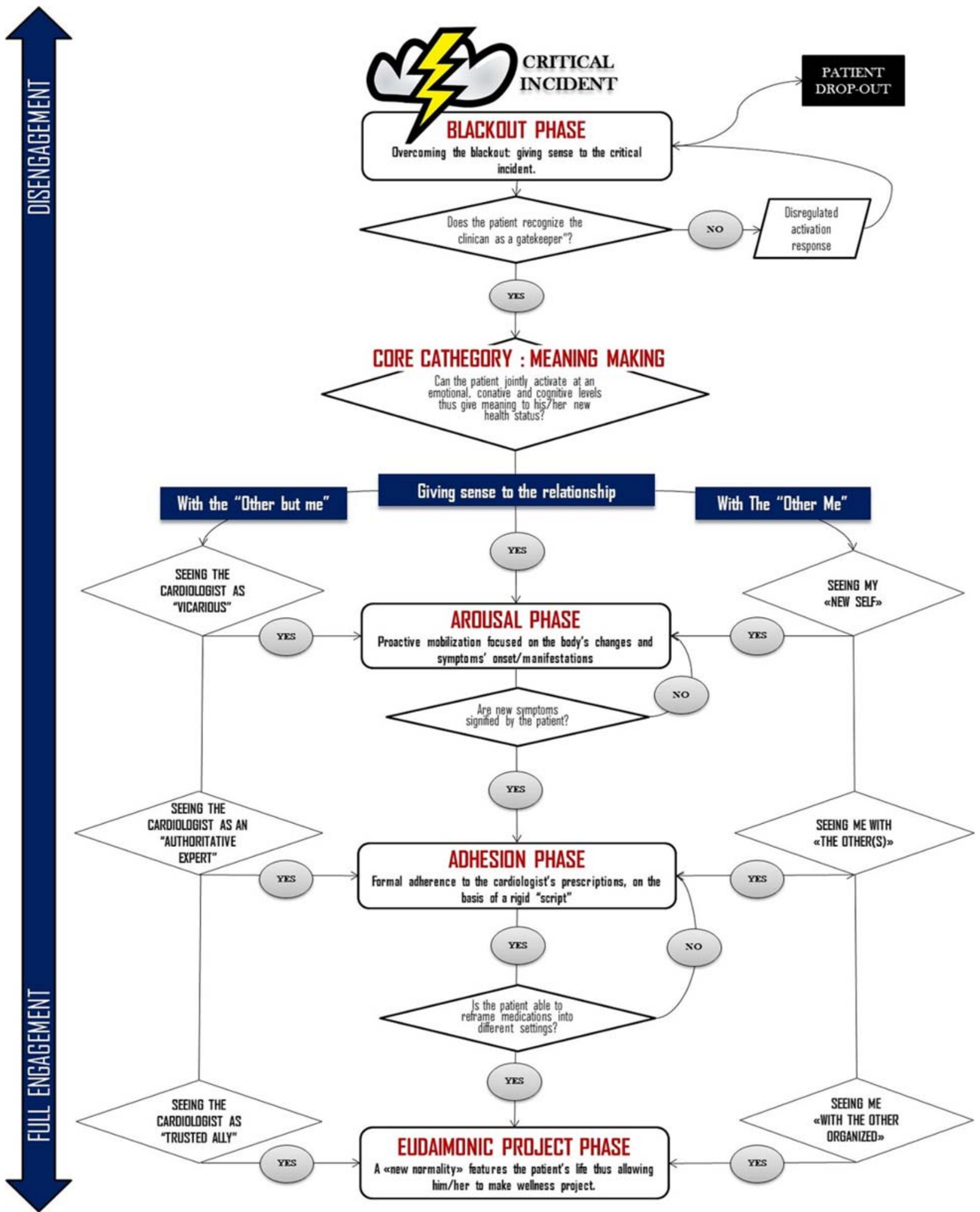

Figure 1 Theoretical model: the process of patient engagement in patients with heart failure (HF).

happened before understanding what will be. (54-year-old male patient with NYHA Class III HF)

I needed to be reassured...and to understand that what I was feeling was not strange or wrong...I only wanted doctor told me that it was normal. (60-year-old female patient with NYHA Class III HF)

I think it is important that between you and your physician a compassionate relation sets up. Patients need for 
human relations not for I mean, I would like a physician that make you feel welcomed; that is close to you and show you that he/she is genuine interested in you and in your health condition. This is the essential condition to led to patients to take care of his/her own health. (54-year-old female patient with NYHA Class III HF)

I can't do anything for my husband...I was like shocked. (Caregiver, wife)

\section{Managing arousal: seeing myself in a new light}

In the subsequent phase of 'arousal', patients feel scared by having been diagnosed with HF. This emotional condition makes them hyper attentive of every symptom their body produces. Symptoms are conceived in this phase as an 'alarm bell', which makes the patient worried and risks activating dysregulated emotional responses in them.

When I perceive a new symptom from my body, I feel really scared and $\mathrm{I}$ am in a tizzy. (60-year-old female patient with NYHA Class III HF)

Symptoms make me feel worried and rather than going to my doctor I would like to escape. (54-year-old female patient with NYHA Class III HF)

Patients have more information than in the previous phase about what happened to them and the causes of their condition, although still stereotypical and superficial. Moreover, they still feel behaviourally unequipped to effectively manage their new condition. In this phase, the physician is conceived by the patient as a 'vicarious' or 'protective father' who should help the patient to work on the facts, impressions and emotions that they find difficult to cope with. This allows the patient to test behavioural caring patterns and learn to manage emotional response to cope with the new health condition.

I met a doctor really careful in explaining me everything I asked her. Once, I experienced a stab and I right away thought of death. Fortunately I took courage and I told her my worries, She told me that it was not an alarming symptom even if she understood my concerns. This made me immediately feel well. (54-year-old female patient with NYHA Class III HF)

When coping with the new condition by themselves is not possible, individuals seem to enter in to contact with their new self and role (as a patient) and legitimise the health professional, who may supply them. Patients' levels of awareness about the disease and its impact on the self and their ability to develop a trusted connectedness with healthcare providers influenced their perceptions of HF. This helps patients to develop skills to integrate new knowledge, which in turn helps in managing their medical prescription. In this phase, patients revealed how they were challenged to integrate new information, adhere to complex medication regimens and lifestyle changes, and navigate an ever-changing health system. In this phase, caregivers act like nurses thus taking care of the disease management-related activities that the patients are not able to do by themselves.

I know that everything takes time. But is so frustrating because I don't know what doctor, what form to give who, and there's different doctors for everything that tell you many many things and I often can't remember anything when I go out of the visit room. (75-year-old male patient with NYHA Class II HF)

When I am at home, in front of the pillars and try to do everything as my doctor told me...it is not easy and I often fail in doing exactly what I should do. (54-year-old female patient with NYHA Class III HF)

I completely assist my father when he has to take medications or need to go to the doctor for the followups... even if I need to be strongly guided by the doctors because I am not so confident with this disease. (Caregiver, son)

\section{Learning to self-manage: hanging on to the cardiologist as}

\section{an authoritative expert.}

The 'adhesion' phase comes when patients have enough knowledge and behavioural skills to effectively adhere to medical prescriptions and feel sufficiently confident in their own emotional strength to cope with their health condition. The label 'adhesion' was chosen as it well suggests the act of sticking to something, either literally or figuratively: in this case the patients totally rely on their cardiologist's advice. Patients described how they transitioned into regular care by learning to assimilate the diagnosis of $\mathrm{HF}$ and its medications into their daily routine without losing their sense of self, relationships, jobs or their normalcy. Successfully moving through this process entailed developing self-confidence and gaining personal insights. In this phase, patients seemed to have a good understanding of what was happening to their heart, but still had little comprehension of what many of their heart medications were intended to achieve. Moreover, they cannot enact medical prescriptions when some contextual conditions vary (ie, when they go on holiday).

For example, when a patient coughs and this symptom annoying him, he tends to focus his attention on this body signal even if for us (doctor) it doesn't care. Then this symptom becomes a sort of trigger that leads patients to indiscriminately search for information to solve the problem. However, they often are not equipped to search for the right information and to find the right source of information because they have not acquired the right skills to distinguish a severe symptom from an innocuous one. (Physician)

I always follow what the doctor tells me. Everyone is good at something different and I am not a health specialist. I know it is modern to have something to say about 
everything, even something I am not good at, but, in this moment I can't and this is not my case. (70-year-old male patient with NYHA Class II HF)

In this phase, patients succeed in understanding and managing new symptoms based on physician counselling, and on the increasing awareness about their body's signals. Patients revealed the need to hang on to the cardiologists' authority and prescriptions, which they considered as a 'lifeline', waiting for the time when they will be able and self-confident to self-manage. Other sources of information such as the internet, friends, neighbours and support groups are used as means to collect information to be discussed with the physician. The physician is perceived as an authoritative expert and this allows patients to feel confident and not alone when engaging in self-management, not only in regard to drugs but also to physical activity, healthy diet regimen, stress management and effective symptom monitoring. It is notable that patients refer to the cardiologist as the main point of reference for their global HF management and do not make use of other sources of information to manage their disease. GPs are sometimes asked to give them general health advice.

No! I leave myself on doctor' hands because for this he go many years to school! (70-year-old male patient with NYHA Class III HF)

I prefer not to go on the Internet...because it is so confusing...my doctor [the cardiologist] makes me quiet and thanks to him I succeed in staying healthy! (75-year-old male patient with NYHA Class II HF)

It generally leads them to employ positive coping strategies and to accept the guidance of an authoritative figure as a reliable point of reference. Rather than seeking knowledge to support self-care, participants still preferred to relinquish responsibility for management to their physicians even if they recognised that they themselves also have a role in maintaining their health. The vast majority of patients expressed a 'blind' or strong faith in their physicians to make decisions on their behalf and would follow professionals' advice regarding self-care without seeking knowledge of HF.

I have a role in my care and I always have had my own responsibilities in obeying them. (74-year-old female patient with NYHA Class III HF)

I am not a substitute of the doctor, but I think to be able to help my husband with his treatments because in these years I learned a lot of things such as how to maintain a correct diet and to do what make me healthy! (74-year-old female patient with NYHA Class III HF)

Further, the caregivers, who until now are not perceived by the patient as a solid anchor, at this stage become sufficiently skilled to facilitate the process of patients' engagement by supporting them both at an emotional and practical level. In this phase, the caregivers are able to provide effective support to patients as they have gained a valid repertoire of disease management skills to deal with the unpredictable and sudden variations of the patients.

My wife asks me to help her when she has to go to the doctor...I usually take notes of drugs and dietary suggestions...then I emotionally support her when she goes down... (Caregiver, husband)

Help me in making sustainable life plans: the physician as a trusted ally

After having finally accepted the disease, a 'new normality' feature enters the patients' life thus allowing him/her to make life plans-sometimes thus passing from the 'adhesion' to the 'eudaimonic project' phase, which may be considered a full engagement status (see figure 1). Inspired by the positive psychology movement, we used the term 'eudaimonic project' to indicate a general state of wellbeing that could be achieved through the patients' personal development and growth, and through finding meaning in their lives. In this phase, the doctor is required to support the patients in identifying tailor-made and context-based disease management strategies and to help the patients in making renewed life plans. The patients in this phase described their doctor as a 'trusted ally' they rely on and of whom they ask for counselling on demand. The doctor succeeds in this role if he is able to provide the patient with a vision for the future and to help the patient to reframe care prescriptions into different settings.

Yes, I do help the doctor because I live with my medical condition and I am experienced. I have had it for years. I know my problem, I know myself and I know my body, so I would report anything new or different that would help the doctor. (54-year-old female patient with NYHA Class III HF)

The patient, in this phase, becomes an experienced testimonial of good self-care practice able to become, in turn, a caregiver of others similar to him/her. To pass from the adhesion to the eudaimonic project phase patients need to recognise in themselves an autonomous and skilled actor within the healthcare context.

Finally, this phase of full engagement features patients who have become co-constructors of their health, capable of enacting meaningful health management that allows them to make improve their quality of life. Patients have fully elaborated their health condition and accepted that the patient self is only one of their possible selves. They are also able to recognise their internal resources as useful to project satisfactory life trajectories for their future.

For me as a person, them taking care of me and me making a commitment to do it was wonderful [...] I wanted to be engaged in taking care of my heart. I felt it was more of a two way thing [...] I felt I was making a big contribution to my recovery [....] I felt empowered and 
hopeful for my future. (75-year-old male patient with NYHA Class II HF)

In this phase, patients are able to effectively search for focused and updated information about their disease and medications. This allows them to give full sense to their health experience; moreover, they have fully elaborated the impact of their health condition on their daily life and are able to effectively enact healthy behaviours at the right time even when contexts change. Patients who reached this status have also developed a new perspective towards their disease that now can be thought of and integrated in a wider life project. Informal caregivers enact the role of a 'life buddy', who shares with the patients the whole life experience beyond illness. The main need of the caregiver in this case is to discover new life potentiality with his/her loved one and to be supportive in a renovated social inclusion.

My husband became autonomous and now he can see again our future. (Caregiver, wife)

We now need to look at our future...unless my disease. (75 year-old male patient with NYHA Class II HF)

\section{DISCUSSION}

This study showed how patient engagement within the HF care setting is developed and maintained, or inhibited. Patients with HF describe their engagement in healthcare as a process-like and multidimensional experience resulting from the combined cognitive, emotional and conative enactment of individuals towards their health management. These experiential dimensions play specific driving roles in the subsequent phases of the process (blackout, arousal, adhesion and eudaimonic project), thus confirming previous findings with patients with diabetes. $^{30}$

Yet, the model that emerged illustrates that patient engagement is based on a meaning-making process enacted by the patient after the critical event (HF). This implies patients' ability to give sense to their care experience and, to their disease, symptomatology and treatments and their changes along their illness course. Moreover, data revealed that the possibility for patients to enter the process of engagement is connected to their capacity to make meaningful their relationship with the other me (ie, his/her new identity as a patient) and with the other but me (ie, the other/s involved in the care relationship, mainly the cardiologist; see figure 1).

Our results show some similarity with other conceptualisations of patient engagement currently present in the literature. Hibbard et $a l^{43}$ describes engagement as "the patients' motivation, knowledge, skills, and confidence to make effective decisions to manage their health," thus highlighting the importance of fostering patients' ability to improve their health literacy and enact healthy behaviours. Also, Gruman et $a l^{24}$ conceives patient engagement as a set of behaviours and actions that allow individuals to effectively manage their health in order to obtain the greatest benefits from their healthcare. The model emerging from this study, although confirming the relevance of the cognitive and behavioural components of the engagement process, clearly casts light on the crucial role the patients' emotional elaboration of their disease engage in their care. Our results find confirmation in previous frameworks that represent phases of cognitive readiness for behavioural change. ${ }^{44-47}$ According to these approaches, a staged view of patient engagement suggests that a full engaged status is the final element in a series of cognitive, emotional and behavioural changes and disease-related events and experiences $^{48}$; and that patient success at any point in the process may depend on success in earlier phases. We hypothesise that patients need to sequentially pass through each of the identified phases of the process on the way to becoming effectively engaged in their health management. These phases have some similarities with the stages of change in the Transtheoretical Model, ${ }^{49}$ which includes precontemplation, contemplation, preparation, action and maintenance stages. The Transtheoretical Model emphasises motivation and readiness but does not explicitly deal with issues of emotional elaboration and disease acceptance. This model mainly focuses on the behavioural and cognitive factors at the base of patients' ability to self-manage. In our model, instead, individuals' emotional elaboration plays an essential role in how they cope with situation of illness, thus influencing their engagement towards their health. The transition from sporadic engagement to regular and effective behaviours to manage their own health involved confronting a variety of meaning-making actions, each of which contributed to the individual's subjective perceptions about the impact of HF on their identity and everyday life, ${ }^{50}$ as shown by previous studies. ${ }^{21}$ When HF interferes with the healthy individual's established identity the person tends to regard himself/herself as a not fully functioning individual such as an inhabitant of a luminal space that narrows his/her identity to one of a patient. Reconstruction of a positive self is not only limited to the patient one contributes to mitigate the disruption of the heart disease but also to facilitate them in the recovery of a 'new normality'.

Moreover, our data cast light on the complex and challenging nature of patients' engagement trajectories when approaching their disease management and the crucial role of the patient-doctor relationship in fostering it. ${ }^{51}$ To deepen the role of the care relationship in promoting the engagement process, further research may also be devoted to understand the role of family caregivers in supporting it.

To trigger the process of engagement, the cardiologist should play the role of a 'gate keeper', a sort of 'relational catalyser', for helping patients to activate the meaning-making actions that sustain the passage from one phase to another. A physician who 'gives the patient a key' to understand what happened and functions as an 
'emotional container' for the patients, could be a catalyser to get this process off the ground. These evidences are consistent with those developed in previous research on patients with diabetes, which clearly underlined the importance of accompanying patients in the elaboration, acceptance and incorporation of their disease (and its treatment) in a new, achievable plan for present and future life trajectories on the bases of their subjective experience of health engagement.

\section{CONCLUSIONS AND PRACTICE IMPLICATIONS}

The diatribe around the dialogue among paternalism or partnership in the patient-doctor relation finds some answers in our results, which suggest the need for a paternalistic approach to care in the early steps of the engagement process as patients in these phases showed a strong preference to defer decision-making to their health provider, because it allows them to take the time to understand the nature and causes of their disease and gradually learn to deal with its implications on their life. On the basis of this, it will be important to find ways of engaging patients only when it is an acceptable status and not an unwanted burden for them. ${ }^{52}$

Our results suggest the need for considering the patients' direct experience of engagement with their disease management in order to give the patients the power to choose their position towards the doctor and, more in general, towards healthcare. ${ }^{53}$

This study offered insights towards the dynamics that feature the HF patients' engagement experience and cast light on the individual and relational processes that occur when this process develops. In particular, our results strongly highlight the crucial role of the physician in fostering the engagement process as their behaviours may reinforce or challenge patients' ability to engage in the healing process. Moreover, making patients autonomous in managing their care means that the doctor should gradually lead the patient to acquire the skills and confidence to effectively engage in the care process. This means also to attune communication style and adopted vocabulary to the level of patients' experience and understanding of their disease condition-as suggested by other studies in this field. ${ }^{54}{ }^{55}$ According to this statement, new technologies for health should also be employed bearing these premises in mind. ${ }^{56}$ In the early phases of the process, it is reasonable that the patients need to delegate the responsibility of decisions about their care to the physicians. It is hoped that our model and its practical implication for the patient-doctor relationship may help clinicians to think in a fresh way about encounters with patients and about their role in fostering their health engagement. This also implies the need for attuning the patient-doctor relations to the meaning-making process enacted by patients with $\mathrm{HF}$ along their engagement continuum. This model also well underlines the importance of not merely fostering the patients' health literacy but also providing behavioural education. Patients should be supported in their process of emotional elaboration of their illness experience and identity reconfiguration in order to maintain their daily life in spite of the disease. ${ }^{58}$ Future research should be aimed at deepening the results by studying the experiential perspectives of the other actors involved in the healthcare. For instance, to better understand the possible role of GPs and physicians of other specialties (ie, especially in diabetes and renal care) in managing patients with HF may be valuable for translating this study's implications from the hospital settings to ambulatory care. Other countries also have specialist nurses and patients with HF who come into contact with other professionals such as physiotherapists or dieticians and these are missing from our results. Based on our data, the main figure present in the patient engagement experience is the hospital cardiologist. It is possible that these results may depend on cultural and organisational specificities. This point suggests the need for further crosscultural investigation to test the transferability of this model to other healthcare systems. Moreover, in order to improve the study evidences, a more articulated data collection and analysis according to patient's age and comorbidity-including patients affected by advanced HF (NYHA IV)—would be worthwhile. Finally, it would be useful to extend this study by collecting stories of dissatisfaction with care services and health providers in order to better address patients' unmet needs when engaging in their care.

\section{Author affiliations}

${ }^{1}$ Faculty of Psychology, Università Cattolica del Sacro Cuore, Milan, Italy ${ }^{2}$ Department of Health Sciences, Università degli Studi di Milano, Milan, Italy ${ }^{3}$ Department of Clinical Sciences and Community Health, Università degli Studi di Milano, Milan, Italy

Acknowledgements The authors would like to thank all of the patients, physicians and caregivers who participated in this study. All the authors confirm that all patients' personal identifiers have been removed or disguised so the patient/person(s) described are not identifiable and cannot be identified through the details of the story.

Contributors SB, GG and EV gave their substantial contributions to conception and design, acquisition of data, or analysis and interpretation of data; SB, MS, GG and EV drafted the article and revised it critically for important intellectual content; SB, GG, EV, FL and ACB approved the version to be published.

Funding This research received no specific grant from any funding agency in the public, commercial or not-for-profit sectors.

Competing interests None.

Patient consent Obtained.

Ethics approval The institutional review board of the San Paolo University Hospital, Italy (Number 12904) approved this study.

Provenance and peer review Not commissioned; externally peer reviewed.

Data sharing statement No additional data are available.

Open Access This is an Open Access article distributed in accordance with the Creative Commons Attribution Non Commercial (CC BY-NC 4.0) license, which permits others to distribute, remix, adapt, build upon this work noncommercially, and license their derivative works on different terms, provided the original work is properly cited and the use is non-commercial. See: http:// creativecommons.org/licenses/by-nc/4.0/ 


\section{REFERENCES}

1. Guha K, McDonagh T. Heart failure epidemiology: European perspective. Curr Cardiol Rev 2013;9:123-7.

2. Krum H, Abraham WT. Heart failure. Lancet 2009;373:941-55.

3. Evangelista LS, Shinnick MA. What do we know about adherence and self-care? J Cardiovasc Nurs 2008;23:250-63.

4. Zambroski $\mathrm{CH}$. Qualitative analysis of living with heart failure. Heart Lung 2003;32:32-40.

5. Rogers AE, Addington-Hall JM, Abery AJ, et al. Knowledge and communication difficulties for patients with chronic heart failure: qualitative study. BMJ 2000;321:605-7.

6. Jerant A, Fenton JJ, Bertakis KD, et al. Satisfaction with health care providers and preventive care adherence: a national study. Med Care 2014;52:78-85.

7. Rogers A, Hassel K, Nicolaas G. Demanding patients? Analysing the use of primary care. Buckingham: Open University, 1999.

8. Alexander JA, Hearld LR, Mittler JN, et al. Patient-physician role relationships and patient activation among individuals with chronic illness. Health Serv Res 2012;47:1201-23.

9. Moser DK, Dickson V, Jaarsma T, et al. Role of self-care in the patient with heart failure. Curr Cardiol Rep 2012;14:265-75.

10. Buck HG, Lee CS, Moser DK, et al. Relationship between self-care and health-related quality of life in older adults with moderate to advanced heart failure. J Cardiovasc Nurs 2012;27:8-15.

11. Seto E, Leonard KJ, Cafazzo JA, et al. Self-care and quality of life of heart failure patients at a multidisciplinary heart function clinic. $J$ Cardiovasc Nurs 2011;26:377-85.

12. van der Wal $\mathrm{M}$, Jaarsma $\mathrm{T}$, et al. Compliance in heart failure patients: the importance of knowledge and beliefs. Eur Heart $J$ 2006;27:343-440.

13. van der Wal $\mathrm{MH}$, van Veldhuisen $\mathrm{DJ}$, et al. Compliance with non-pharmacological recommendations and outcome in heart failure patients. Eur Heart J 2010;31:1486-93.

14. Wang SP, Lin LC, Lee CM, et al. Effectiveness of a self-care program in improving symptom distress and quality of life in congestive heart failure patients: a preliminary study. J Nurs Res 2011;19:257-66.

15. Lee CS, Moser DK, Lennie TA, et al. Event-free survival in adults with heart failure who engage in self-care management. Heart Lung 2011;40:12-20.

16. Forbat L, Cayless S, Knighting $\mathrm{K}$, et al. Engaging patients in health care: an empirical study of the role of engagement on attitudes and action. Patient Educ Couns 2009;74:84-90.

17. Cassel CK, Guest JA. Choosing wisely: helping physicians and patients make smart decisions about their care. JAMA 2012;307:1801-2.

18. Judson TJ, Detsky AS, Press MJ. Encouraging patients to ask questions: how to overcome "white-coat silence" JAMA 2013;309:2325-6.

19. Europe E, Tyni-Lenné R. Qualitative analysis of the male experience of heart failure. Heart Lung 2004;33:227-34.

20. Buetow S, Goodyear-Smith F, Coster G. Coping strategies in the self-management of chronic heart failure. Fam Pract 2001;18:117-22.

21. Yu DS, Lee DT, Kwong AN, et al. Living with chronic heart failure: a review of qualitative studies of older people. J Adv Nurs 2008;61:474-83.

22. Jeon $\mathrm{YH}$, Kraus SG, Jowsey $\mathrm{T}$, et al. The experience of living with chronic heart failure: a narrative review of qualitative studies. BMC Health Serv Res 2010;10:77-82.

23. Field K, Ziebland S, McPherson A, et al. 'Can I come off the tablets now?' A qualitative analysis of heart failure patients' understanding of their medication. Fam Pract 2006;23:624-30.

24. Gruman J, Rovner MH, French ME, et al. From patient education to patient engagement: implications for the field of patient education. Patient Educ Couns 2010;78:350-6.

25. Amico KR. A situated-information motivation behavioral skills model of care initiation and maintenance (simb-cim): an IMB model based approach to understanding and intervening in engagement in care for chronic medical conditions. Health Psychol 2011;16:1071-81.

26. Carman KL, Dardess $P$, Maurer M, et al. Patient and family engagement: a framework for understanding the elements and developing interventions and policies. Health Aff (Millwood) 2013;32:223-31.

27. Bertoni A, Donato S, Graffigna G, et al. Engaged patients, engaged partnerships: singles and partners in front of an acute cardiac event. Psychol Health Med 2014;15:1-13.

28. Grande SW, Faber MJ, Durand MA, et al. A classification model of patient engagement methods and assessment of their feasibility in real-world settings. Patient Educ Couns 2014:95:281-7.

29. Graffigna G, Barello S, Bonanomi A, et al. Measuring patient engagement: development and psychometric properties of the
Patient Health Engagement (PHE) scale. Front Psychol 2015;6:274 [Epub ahead of print].

30. Graffigna G, Barello S, Libreri C, et al. How to engage type-2 diabetic patients in their own health management: implications for clinical practice. BMC Public Health 2014;14:648.

31. Charmaz K. Constructing grounded theory: a practical guide through qualitative analysis. London: Sage, 2006.

32. Bryant A, Charmaz K, eds. The sage handbook of grounded theory. London: Sage, 2007.

33. Corbin J, Strauss A, eds. Basics of qualitative research: techniques and procedures for developing grounded theory. London: Sage, 2008.

34. Tong A, Sainsbury $P$, Craig J. Consolidated criteria for reporting qualitative research (COREQ): a 32-item checklist for interviews and focus groups. Int J Qual Health Care 2007;19:349-57.

35. Mills J, Bonner A, Francis K. The Development of Constructivist Grounded Theory. Int J Qual Methods 2006;5:1-10.

36. Bennett JA, Riegel B, Bittner V, et al. Validity and reliability of the NYHA classes for measuring research outcomes in patients with cardiac disease. Heart Lung 2002;31:262-70.

37. Miller-Davis C, Marden S, Leidy NK. The New York Heart Association Classes and functional status: what are we really measuring? Heart Lung 2006;35:217-24.

38. Cummings JL. Mini-mental state examination. JAMA 1993;269:2420-1.

39. Hibbard JH, Mahoney ER, Stockard J, et al. Development and testing of a short form of the patient activation measure. Health Serv Res 2005:40:1918-30.

40. Gibbs GR. Qualitative data analysis: explorations with NVivo. Buckingham: Open University Press, 2002.

41. Morisky DE, Bowler MH, Finlay JS. An educational and behavioral approach toward increasing patient activation in hypertension management. J Community Health 1982;7:171-82.

42. Morse JM, Barrett M, Mayan M, et al. Verification strategies for establishing reliability and validity in qualitative research. Int J Qual Methods 2002;1:1-19.

43. Hibbard, JH, Greene J, Tusler M. Improving the outcomes of disease management by tailoring care to the patient's level of activation. Am J Manag Care 2009;15:353-60.

44. Prochaska JO, DiClemente CC, Norcross JC. In search of how people change: applications to addictive behaviors. Am Psychol 1992;47:1102-14.

45. Simpson DD. Modeling treatment process and outcomes. Addiction 2001;96:207-11.

46. Simpson DD, Joe GW. Motivation as a predictor of early dropout from drug abuse treatment. Psychotherapy 1993;30:357-68.

47. Johnson SS, Driskell MM, Johnson JL, et al. Efficacy of a transtheoretical model-based expert system for antihypertensive adherence. Dis Manag 2006;9:291-301.

48. Mowbray CT, Cohen E, Bybee D. The challenge of outcome evaluation in homeless services: engagement as an intermediate outcome measure. Eval Program Plann 1993;16:337-46.

49. Neimeyer RA, Raskin JD. Constructions of disorder: meaning-making frameworks for psychotherapy. Washington, DC: American Psychological Association, 2000.

50. Levine RM, Reicher SD. Making sense of symptoms: self-categorization and the meaning of illness and injury. $\mathrm{Br} J \mathrm{Soc}$ Psychol 1996;35:245-56.

51. Ironside PM, Scheckel M, Wessels C et al. Experiencing chronic illness: cocreating new understandings. Qual Health Res 2003;13:171-83.

52. Coulter A. Paternalism or partnership? Patients have grown up-and there's no going back. BMJ 1999;319:719.

53. Graffigna G, Barello S, Riva G. Technologies for patient engagement. Health Aff (Millwood) 2013;32:1172.

54. Barello S, Graffigna G. Engaging patients to recover life projectuality an Italian cross-disease framework. Qual Life Res 2014 doi:10.1007/s11136-014-0846-x [Epub ahead of print].

55. Williams MV, Davis T, Parker RM, et al. The role of health literacy in patient-physician communication. Fam Med 2002;34:383-9.

56. Castro CM, Wilson C, Wang F, et al. Babel babble: physicians' use of unclarified medical jargon with patients. Am J Health Behav 2007;31:S85-95.

57. Graffigna G, Barello S, Riva G. How to make health information technology effective: the challenge of patient engagement. Arch Phys Med Rehabil 2013;94:2034-5.

58. Falk S, Wahn AK, Lidell E. Keeping the maintenance of daily life in spite of chronic heart failure. A qualitative study. Eur J Cardiovasc Nurs 2007;6:192-9. 